\title{
The Complete Loss of Tyrosine Kinase Receptors MET and RON Is a Poor Prognostic Factor in Patients with Extrahepatic Cholangiocarcinoma
}

\author{
YUKI HAYASHI, JUNPEI YAMAGUCHI, TOSHIO KOKURYO, TOMOKI EBATA, \\ YUKIHIRO YOKOYAMA, TSUYOSHI IGAMI, GEN SUGAWARA and MASATO NAGINO \\ Division of Surgical Oncology, Department of Surgery, \\ Nagoya University Graduate School of Medicine, Nagoya, Japan
}

\begin{abstract}
Background: Although the survival of patients with cholangiocarcinoma has improved, the prognosis remains unfavorable. The overexpression of mesenchymal-epithelial transition factor (MET) and recepteur d'origine nantais (RON) has been considered to be indicative of a poor prognosis in some types of cancer. On the other hand, some studies have shown that the expression of MET and RON is a favorable prognostic factor in certain types of tumors. Materials and Methods. Based on the immunohistochemical analysis of MET and RON, 290 patients who underwent resection for extrahepatic cholangiocarcinoma were divided into three groups: MET/RON-negative, -intermediate, and -positive. The associations between MET/RON expression and clinicopathological features, including prognosis, were analyzed. Results: MET/RON-negativity was associated with nodal metastasis and advanced pathological stage. The overall 5-year survival rates were significantly lower in the MET/RONnegative and MET/RON-positive groups than in the MET/RONintermediate group $(28.3 \%, 32.4 \%$ and $48.5 \%$, respectively; $p=0.01)$. Conclusion: The complete loss of one or both MET and RON, as well as their overexpression, is a poor prognostic factor in patients with extrahepatic cholangiocarcinoma, probably due to the high rate of lymph-node metastasis.
\end{abstract}

Cholangiocarcinoma is a highly malignant invasive carcinoma arising from the ductal epithelium of the bile duct. Both intrahepatic cholangiocarcinoma and extrahepatic

Correspondence to: Junpei Yamaguchi, MD, Ph.D., Division of Surgical Oncology, Department of Surgery, Nagoya University Graduate School of Medicine, 65 Tsurumai-cho, Showa-ku, Nagoya, Aichi 466-8550, Japan. Tel: +81 527442222, Fax: +81 527442230, e-mail: jumpei@med.nagoya-u.ac.jp

Key Words: Mesenchymal-epithelial transition factor, recepteur d'origine nantais, extrahepatic cholangiocarcinoma. cholangiocarcinoma (EHCC) have a poor prognosis, partly because cholangiocarcinoma is difficult to diagnose at an early stage, and most patients have unresectable disease at first diagnosis. Surgical resection is the only curative therapy, but the recurrence rate is high, and prognosis is poor even after surgical resection (1-3). Although some studies demonstrated that gemcitabine-based chemotherapy improves prognosis $(4,5)$, the benefit of chemotherapy for cholangiocarcinoma has not been established. Currently, the development of individualized treatment based on patient characteristics is needed, and molecular-targeted agents might be a desirable option.

Mesenchymal-epithelial transition factor (MET) and recepteur d'origine nantais (RON) are cell surface receptor tyrosine kinases that bind hepatocyte growth factor (HGF) and macrophage-stimulating protein (MSP), respectively. MET and RON are involved in the epithelial to mesenchymal transition (EMT), the process by which epithelial cells obtain a mesenchymal phenotype. EMT is essential not only for tissue repair and organ regeneration but also embryonic development; however, cancer cells can take advantage of this process to acquire enhanced invasive and metastatic capabilities.

The enhanced expression of MET and RON has been reported in various tumor types (6). Missense mutations in $M E T$, which are found in papillary renal cancer (7), childhood hepatocellular carcinoma (8) and gastric cancer (9), can result in the activation of MET signaling and are associated with increased aggressiveness and extensive metastasis of cancer. Increased MET expression is also found in the absence of mutation and is associated with metastasis and poor prognosis in carcinomas of the colon (10), liver (11), pancreas (12), stomach (13), prostate (14), ovary (15) and breast (16). RON overexpression has also been observed in various malignant tumors and is associated with more aggressive features and a poor prognosis (17-22). Crosslinking occurs between MET and RON via the formation of 
hetero-complexes, and transphosphorylation leads to the reciprocal regulation of kinase activity (23), suggesting that MET and RON expression can work cooperatively in cancer cells. Accordingly, our previous study revealed that among patients with advanced-stage perihilar cholangiocarcinoma, those with increased tumor expression of both MET and RON had a significantly worse prognosis (24).

On the other hand, some studies have shown that the expression of MET and RON is a favorable prognostic factor in certain types of cancer, such as diffuse large B-cell lymphoma $(25,26)$ and breast cancer $(27,28)$, indicating that both complete loss and overexpression of MET and RON may be factors associated with poor prognosis of patients with malignant tumors.

In this study, in order to clarify the true impact of MET or RON expression in EHCC, the expression of MET and RON were determined, and potential associations with clinicopathological features and prognosis were analyzed.

\section{Patients and Methods}

Patients. From 2001 to 2010, 91 patients with distal cholangiocarcinoma underwent resection at our Department. The addition of 248 patients with resected perihilar cholangiocarcinoma (previously described) (24) yielded a total of 339 enrolled patients. Patients with distant metastasis (M1) with/without noncurative resection (R2) were excluded ( $\mathrm{n}=49)$; thus, 290 patients were analyzed (Figure 1). Clinicopathological findings were obtained from prospectively collected data. Factors related to tumor progression, such as T, N, and $M$ stage and residual tumor classification, were determined in accordance with the TNM classification of the Union for International Cancer Control (UICC) (29).

Immunohistochemistry. Primary antibody total c-MET (clone SP44, rabbit monoclonal; Ventana Medical Systems, Inc., Tucson, AZ, USA) and anti-RON (clone EP1132Y, rabbit monoclonal; Abcam, Inc., Cambridge, UK) were purchased. Immunohistochemistry for MET and RON was performed using a Discovery XT automated slide preparation system (Ventana Medical Systems, Inc.) according to the manufacturer's protocol. The surgically resected specimens were embedded in paraffin. Before staining, the paraffin-embedded sections were blocked with $1 \%$ nonfat milk. For MET staining, the slides were incubated with the MET antibody with an amplification kit (Ventana Medical Systems, Inc.) for $60 \mathrm{~min}$ at room temperature. For RON staining, the slides were incubated with the RON antibody (1:100 dilution) for $12 \mathrm{~h}$ at room temperature. Primary antibody was detected using a diaminobenzidine (DAB) Map Detection Kit (Ventana Medical Systems, Inc.). Universal secondary antibody (Ventana Medical Systems, Inc.) was applied for $48 \mathrm{~min}$ at room temperature. The slides were counterstained with hematoxylin II (Ventana Medical Systems, Inc.) for $4 \mathrm{~min}$.

To analyze MET and RON expression, a representative slide from the excised tumor was selected, and the entire tumor part in the slide was assessed. MET and RON expression was then categorized into three groups based on staining density according to previously published studies (30): no expression: -, complete absence of membranous staining; moderate expression: $1+$, faint or partial membranous staining in at least $30 \%$ of cancer cells; or strong expression: $2+$, strong and complete staining in at least $30 \%$ of cancer cells. Representative images of MET and RON expression are shown in Figure 2. In the current study, coexpression of MET and RON was also classified into three groups: MET/RON-positive: strong expression of both MET and RON; MET/RON-negative: no expression of either or neither MET and RON; or MET/RONintermediate (neither strongly positive nor negative for MET or RON) (Table I). The tissue sections were evaluated by two observers without knowledge of the clinical data. Any disagreements in the grading of positivity were resolved by discussion between two observers.

Statistical analysis. Categorical variables were compared using the Chi-square test. Continuous variables are presented as the mean $( \pm$ SD) and were compared using ANOVA. Patient survival was determined from the time of surgery to the time of death or most recent follow-up. Cumulative survival rates were analyzed by the Kaplan-Meier method using the log-rank test to compare groups. A multivariate analysis was performed with a Cox proportional hazards model. In all analyses, a value of $p<0.05$ was considered to indicate statistical significance. The data were analyzed using SPSS, version 11 (Chicago, IL, USA).

\section{Results}

Clinicopathological features and MET/RON expression. The numbers of patients with no expression, moderate expression and strong expression were $30(10.3 \%), 127(43.8 \%)$ and $133(45.9 \%)$ for MET and 35 (12.1\%), 124 (42.8\%), and 131 (45.2\%) for RON (Table I). In total, $76(26.2 \%)$ patients had MET/RON-positive tumors, and 56 (19.3\%) patients were in the MET/RON-negative group.

The demographic and clinical characteristics of patients are shown in Table II. The characteristics were compared among the groups with negative, intermediate and positive MET/RON expression. In terms of tumor location, patients with perihilar cholangiocarcinoma were more likely than those with distal disease to be in the MET/RON-negative group $(p<0.001)$. Poorly differentiated tumors with advanced pathology ( $\mathrm{T}$ and $\mathrm{N}$ grades) were frequently found in the MET/RON-negative group. The frequency of patients with advanced pathological stage was significantly higher in the MET/RON-negative group $(p=0.001)$. Of note, when the $\mathrm{N}$ status was compared between the MET/RON-negative group and the other groups (comprising the intermediate and positive groups), advanced $\mathrm{N}$ status were found more frequently in the MET/RON-negative group [55.4\% ( $\mathrm{n}=31 / 56)$ and $40.2 \%(\mathrm{n}=94 / 234)$, respectively; $p=0.039]$. Tumour $\mathrm{N}$ status was not significantly different in the MET/RON-positive group compared to a group comprising the other categories $[44.4 \%(n=95 / 214)$ and $39.5 \%(n=30 / 76)$, respectively; $p=0.457]$. These data suggest that the complete loss of MET or RON, but not their overexpression, is associated with nodal metastasis and advanced pathological stage. Other characteristics, including age, sex, lymphatic invasion, venous invasion, histopathological classification and residual tumor classification, were not significantly different between these groups. 


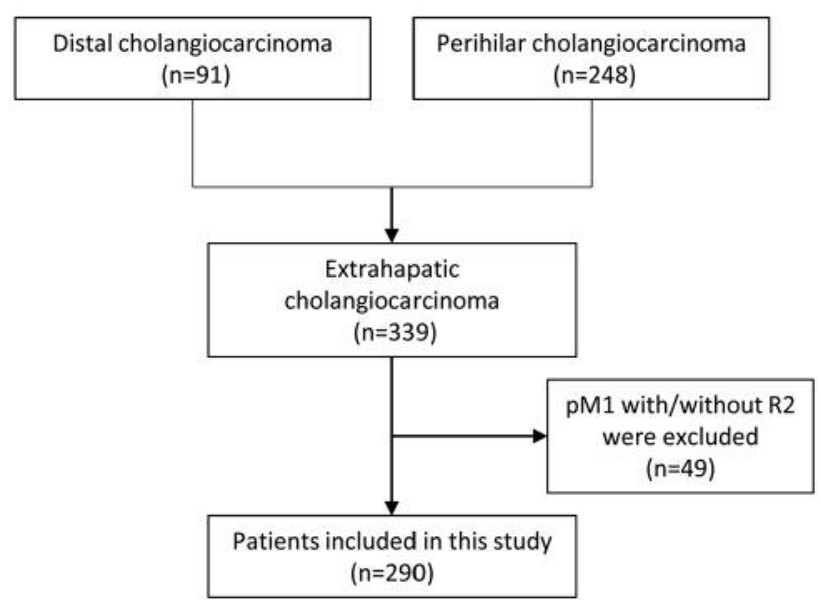

Figure 1. Flow diagram of patients who were included or excluded from this study.

Survival. The 5-year survival rate tended to be better for patients with moderate (1+) MET expression than for those with negative (0) or strong (2+) MET expression (47.1\% vs. $30.0 \%$ and $36.3 \%$, respectively; $p=0.223$ ) and was significantly better for the RON $1+$ group compared with the RON 0 and the $2+$ group $(47.3 \%$ vs. $28.1 \%$ and $37.1 \%$, respectively; $p=0.042$ ) (Figure $3 \mathrm{~A}$ and $\mathrm{B}$ ). Based on the hypothesis that the combined status of MET and RON expression represents a precise prognostic factor, MET/RON classification was employed. The 5-year survival rate was significantly higher for the MET/RON-intermediate group than for the groups with negative or positive MET/RON expression $(48.5 \%$ vs. $28.3 \%$ and $32.4 \%$, respectively; $p=0.010$ ), but there was no significant difference between the MET/RON-negative and MET/RON-positive groups (Figure 3C).

In the univariate analysis, RON expression, MET/RON expression, lymphatic vessel invasion, venous invasion, histopathological classification, $\mathrm{pT}, \mathrm{pN}$, pStage and resection margin (R status) were significantly associated with poor prognosis (Table III). Among these factors, seven (excluding RON expression alone and pStage) were included in the multivariate analysis. MET/RON positivity was identified as an independent prognostic factor $(p=0.007)$, as were other factors such as venous invasion $(p=0.006), \mathrm{pN}(p<0.001)$, and resection margin $(p=0.001)$. Unlike MET/RON positivity, negative MET/RON expression was not identified as an independent factor in the multivariate analysis, probably because complete loss of MET/RON is associated with advanced nodal status and pathological stage and thus cannot be an independent factor if these features are included in the analysis.
Table I. Frequency of immunohistochemical expression of mesenchymalepithelial transition factor (MET) and recepteur d'origine nantais (RON).

\begin{tabular}{|c|c|c|c|c|c|}
\hline & \multicolumn{3}{|c|}{ MET score } & \multirow[b]{2}{*}{ Total } \\
\hline & & 0 & $1+$ & $2+$ & \\
\hline \multirow{3}{*}{$\begin{array}{l}\text { RON } \\
\text { score }\end{array}$} & 0 & $9(3.1 \%)$ & $18(6.2 \%)$ & $8(2.8 \%)$ & $35(12.1 \%)$ \\
\hline & $1+$ & $15(5.2 \%)$ & $60(20.7 \%)$ & $49(16.9 \%)$ & $124(42.8 \%)$ \\
\hline & $2+$ & $6(2.1 \%)$ & $49(16.9 \%)$ & $76(26.2 \%)$ & $131(45.2 \%)$ \\
\hline & total & $30(10.3 \%)$ & $127(43.8 \%)$ & $133(45.9 \%)$ & 290 \\
\hline & \multicolumn{5}{|c|}{ MET/RON-negative $n=56(19.3 \%)$} \\
\hline$\square$ & \multicolumn{5}{|c|}{ MET/RON-intermediate $n=158(54.5 \%)$} \\
\hline$\square$ & \multicolumn{5}{|c|}{ MET/RON-positive $n=76(26.2 \%)$} \\
\hline
\end{tabular}

\section{Discussion}

In this study, we separated patients with EHCC into three groups according to the level of MET and RON coexpression: negative, intermediate or positive. We revealed that the 5-year survival rate was significantly lower among patients in the MET/RON-positive and MET/RON-negative groups compared with those in the MET/RON-intermediate group. These data suggest that both complete loss and overexpression of MET/RON are poor prognostic factors.

MET and RON are receptor tyrosine kinases that are associated with cancer progression, invasion and metastasis, and the expression of MET and RON has been reported as a poor prognostic factor in a variety of cancer types. Our previous study demonstrated that double positivity for MET and RON was an independent poor prognostic factor in patients with advanced stage perihilar cholangiocarcinoma (24). This result is consistent with those of other studies revealing that MET overexpression is a poor prognostic factor in cancer types such as cholangiocarcinoma $(30,31)$; however, the results of our previous study were obtained by limiting the analysis to patients with advanced-stage disease, and thus, the number of patients was relatively small $(n=169)$. Therefore, it is unclear if MET/RON has a prognostic impact in early-stage cholangiocarcinoma and if this prognostic factor can be applied to all cases of EHCC, including distal bile duct carcinoma. In order to accurately and extensively investigate the impact of MET and RON expression on patients with EHCC, patients with early-stage cholangiocarcinoma with/without distal bile duct carcinoma were included in this study. Thus, a large number of patients $(n=290)$ were analyzed, and we revealed that MET/RON expression is a general prognostic factor in EHCC.

While the overexpression of MET or RON is likely associated with aggressive tumor behavior, some reports have shown that MET and RON expression is a favorable prognostic factor in diffuse large B-cell lymphoma and 


\section{MET 0}

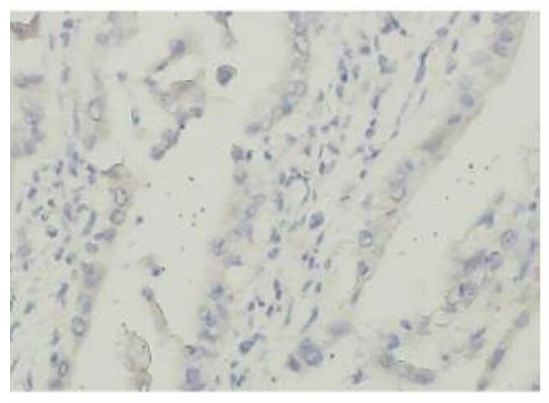

RON 0

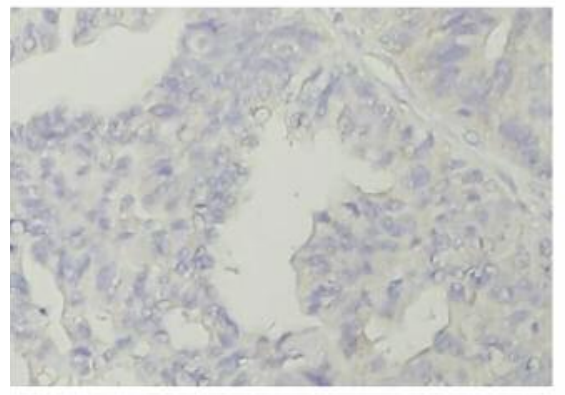

MET 1+

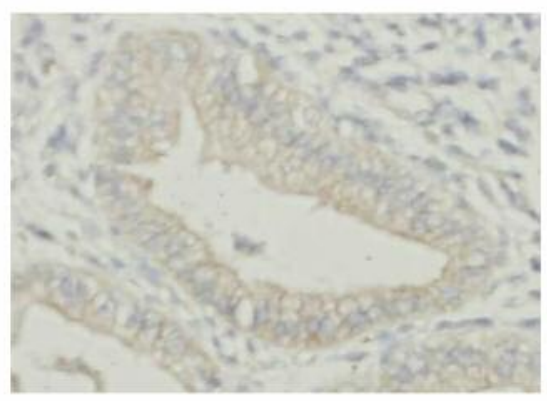

RON 1+

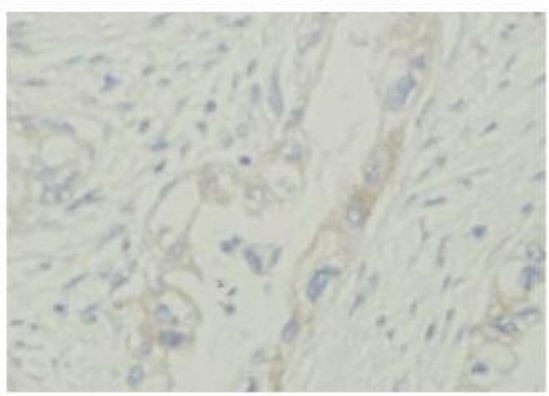

MET 2+

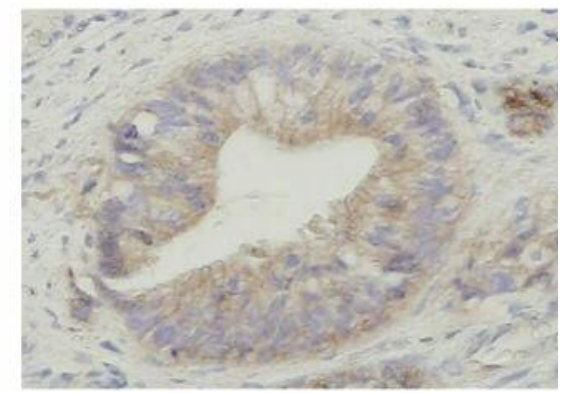

RON 2+

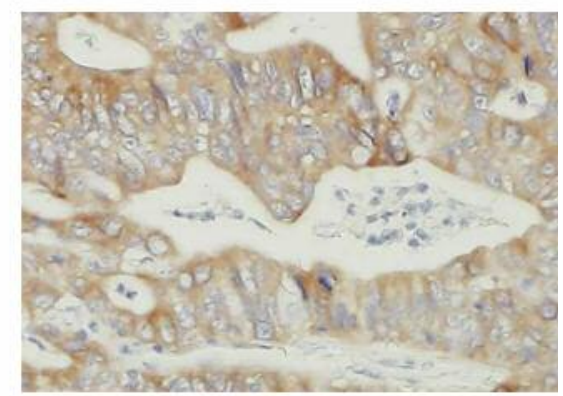

Figure 2. Representative images of mesenchymal-epithelial transition factor and recepteur d'origine nantais expression.

Table II. Clinicopathological features according to expression of mesenchymal-epithelial transition factor (MET) and recepteur d'origine nantais (RON).

\begin{tabular}{|c|c|c|c|c|c|c|}
\hline \multirow[b]{2}{*}{ Characteristic } & & \multirow[b]{2}{*}{$\begin{array}{c}\text { Total } \\
(\mathrm{n}=290)\end{array}$} & \multicolumn{3}{|c|}{ MET/RON } & \multirow[t]{2}{*}{$p$-Value } \\
\hline & & & $\begin{array}{l}\text { Negative } \\
(\mathrm{n}=56)\end{array}$ & $\begin{array}{l}\text { Intermediate } \\
\quad(\mathrm{n}=158)\end{array}$ & $\begin{array}{l}\text { Positive } \\
(\mathrm{n}=76)\end{array}$ & \\
\hline Age years & Mean \pm SD & $65.5 \pm 9.6$ & $64.2 \pm 9.0$ & $65.0 \pm 10.3$ & $67.6 \pm 8.2$ & 0.070 \\
\hline \multirow[t]{2}{*}{ Gender } & Male & $182(62.8 \%)$ & $41(73.2 \%)$ & $95(60.1 \%)$ & $46(60.5 \%)$ & \\
\hline & Female & $108(37.2 \%)$ & $15(26.8 \%)$ & $63(39.9 \%)$ & $30(39.5 \%)$ & 0.197 \\
\hline \multirow[t]{2}{*}{ Tumor location } & Perihilar & $204(70.3 \%)$ & $40(71.4 \%)$ & $127(80.4 \%)$ & $37(48.7 \%)$ & \\
\hline & Distal & $86(29.7 \%)$ & $16(28.6 \%)$ & $31(19.6 \%)$ & $39(51.3 \%)$ & $<0.001$ \\
\hline \multirow[t]{2}{*}{ Lymphatic vessel invasion } & Absent & $80(27.6 \%)$ & $13(23.2 \%)$ & $45(28.5 \%)$ & $22(28.9 \%)$ & \\
\hline & Present & $208(71.7 \%)$ & $41(73.2 \%)$ & $113(71.5 \%)$ & $54(71.1 \%)$ & 0.795 \\
\hline \multirow[t]{2}{*}{ Venous invasion } & Absent & $192(66.2 \%)$ & $38(67.9 \%)$ & $102(64.6 \%)$ & $52(68.4 \%)$ & \\
\hline & Present & $97(33.4 \%)$ & $17(30.4 \%)$ & $56(35.4 \%)$ & $24(31.6 \%)$ & 0.756 \\
\hline \multirow[t]{2}{*}{ Histopatholoy } & Pap/well & $61(21.0 \%)$ & $6(10.7 \%)$ & $39(24.7 \%)$ & $16(21.1 \%)$ & \\
\hline & Other & $229(79.0 \%)$ & $50(89.3 \%)$ & $119(75.3 \%)$ & $60(78.9 \%)$ & 0.088 \\
\hline \multirow[t]{2}{*}{ UICC $\mathrm{pT}$} & $\mathrm{T} 0-2$ & $106(36.6 \%)$ & $16(28.6 \%)$ & $59(37.3 \%)$ & $31(40.8 \%)$ & \\
\hline & T3-4 & $184(63.4 \%)$ & $40(71.4 \%)$ & $99(62.7 \%)$ & $45(59.2 \%)$ & 0.338 \\
\hline \multirow[t]{2}{*}{ UICC $\mathrm{pN}$} & No & $165(56.9 \%)$ & $25(44.6 \%)$ & $94(59.5 \%)$ & $46(60.5 \%)$ & \\
\hline & N1 & $125(43.1 \%)$ & $31(55.4 \%)$ & $64(40.5 \%)$ & $30(39.5 \%)$ & 0.118 \\
\hline \multirow[t]{2}{*}{ UICC pStage } & Stage $0-2$ & $143(49.3 \%)$ & $21(37.5 \%)$ & $71(44.9 \%)$ & $51(67.1 \%)$ & \\
\hline & Stage 3-4 & $147(50.7 \%)$ & $35(62.5 \%)$ & $87(55.1 \%)$ & $25(32.9 \%)$ & 0.001 \\
\hline \multirow[t]{2}{*}{ Residual tumor classification } & R0 & $228(78.6 \%)$ & $43(76.8 \%)$ & $128(81.0 \%)$ & $57(75.0 \%)$ & \\
\hline & $\mathrm{R} 1$ & $62(21.4 \%)$ & $13(23.2 \%)$ & $30(19.0 \%)$ & $19(25.0 \%)$ & 0.537 \\
\hline
\end{tabular}

Pap/well: Papillary/well-differentiated adenocarcinoma; other: moderately or poorly differentiated adenocarcinoma, and adenosquamous carcinoma; UICC: Union for International Cancer Control; R0: no residual tumor; R1: microscopic residual tumor. 

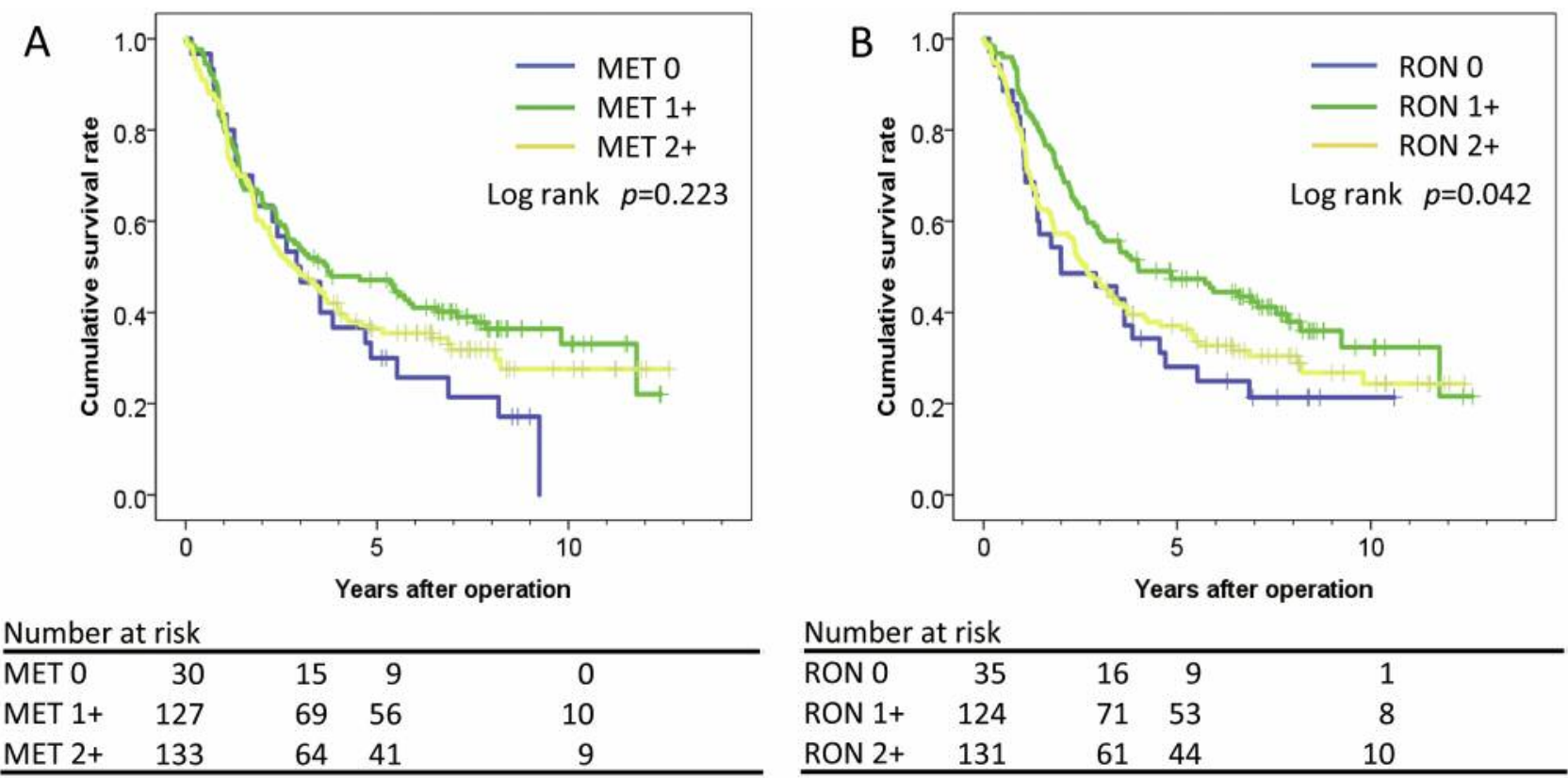

C

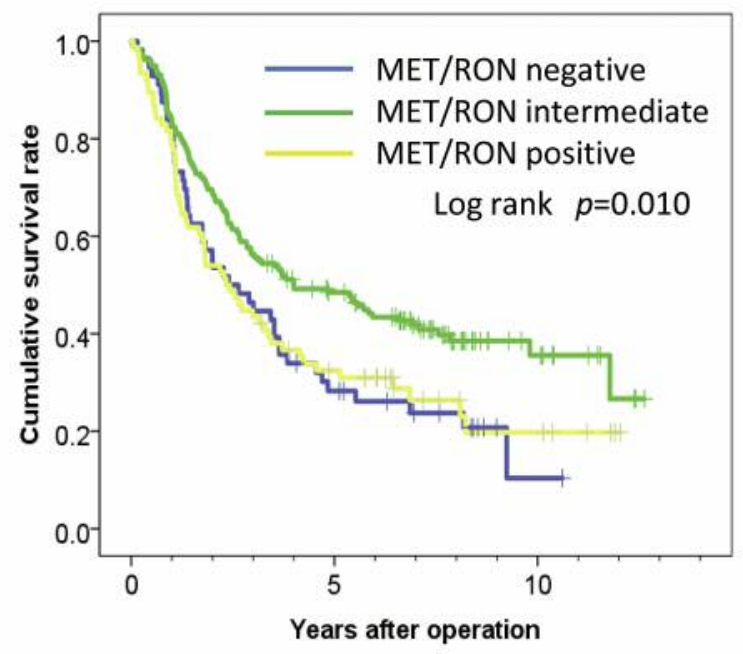

Number at risk

\begin{tabular}{lrrrr}
\hline MET/RON negative & 56 & 26 & 15 & 1 \\
MET/RON intermediate & 158 & 89 & 69 & 12 \\
MET/RON positive & 76 & 33 & 22 & 6 \\
\hline
\end{tabular}

Figure 3. Overall survival according to mesenchymal-epithelial transition factor (MET) (A), recepteur d'origine nantais (RON) (B) and MET/RON (C) expression.

breast cancer (25-28). In patients with cholangiocarcinoma, Aishima et al. reported an inverse correlation between MET overexpression and the presence of lymph-node metastasis: MET positivity was frequent in papillary and welldifferentiated cholangiocarcinomas, and patients with negative staining for c-MET had a significantly shorter survival than those with positive staining (32). These data are partly consistent with the results of this study. Basic research has shown that MET signaling can play a negative role in tumor growth. For instance, the antiproliferative and apoptosis-inducing effects of HGF on certain epithelial malignancies have been shown in previous studies (33-38), 
Table III. Univariate and multivariate analyses for prognostic factors.

\begin{tabular}{|c|c|c|c|c|c|c|c|c|c|}
\hline & & \multirow{2}{*}{$\begin{array}{l}\text { No. of } \\
\text { patients }\end{array}$} & \multicolumn{2}{|c|}{ Survival (\%) } & \multirow{2}{*}{$\begin{array}{c}\text { Median } \\
\text { survival } \\
\text { (years) }\end{array}$} & \multirow{2}{*}{$\begin{array}{c}\text { Univariate } \\
\begin{array}{c}\text { Log-rank } \\
p \text {-value }\end{array}\end{array}$} & \multicolumn{3}{|c|}{ Multivariate } \\
\hline & & & 5-Year & 10-Year & & & $\begin{array}{c}\text { Hazard } \\
\text { ratio }\end{array}$ & $\begin{array}{c}95 \% \\
\text { Confidence } \\
\text { interval }\end{array}$ & $p$-Value \\
\hline \multirow[t]{2}{*}{ Age } & $<65$ Years & 126 & 47.5 & 32.6 & 3.7 & & & & \\
\hline & $\geq 65$ Years & 164 & 34.8 & 22.9 & 2.8 & 0.101 & & & \\
\hline \multirow[t]{2}{*}{ Gender } & Male & 182 & 40.4 & 24.5 & 3.1 & & & & \\
\hline & Female & 108 & 40.3 & 32.2 & 3.0 & 0.551 & & & \\
\hline \multirow[t]{3}{*}{ MET } & 0 & 30 & 30.0 & 0.0 & 2.9 & 0.078 & & & \\
\hline & $1+$ & 127 & 47.1 & 33.1 & 3.7 & & & & \\
\hline & $2+$ & 133 & 36.3 & 27.6 & 2.8 & 0.281 & & & \\
\hline \multirow[t]{3}{*}{ RON } & 0 & 35 & 28.1 & 21.4 & 2.0 & 0.025 & & & \\
\hline & $1+$ & 124 & 47.3 & 32.4 & 4.0 & & & & \\
\hline & $2+$ & 131 & 37.1 & 24.3 & 2.6 & 0.041 & & & \\
\hline \multirow[t]{3}{*}{ MET/RON } & Negative & 56 & 28.3 & 10.4 & 2.4 & 0.009 & 1.268 & $0.872-1.843$ & 0.214 \\
\hline & Intermediate & 158 & 48.5 & 35.5 & 4.0 & & 1 & & \\
\hline & Positive & 76 & 32.4 & 19.8 & 2.3 & 0.015 & 1.601 & $1.140-2.246$ & 0.007 \\
\hline \multirow[t]{2}{*}{ Tumor location } & Perihilar & 204 & 41.2 & 26.9 & 3.2 & & & & \\
\hline & Distal & 86 & 38.5 & 32.1 & 2.7 & 0.935 & & & \\
\hline \multirow[t]{2}{*}{ Lymphatic vessel invasion } & Absent & 80 & 57.2 & 40.4 & 7.6 & & 1 & & \\
\hline & Present & 208 & 34.3 & 22.2 & 2.5 & $<0.001$ & 0.946 & $0.629-1.423$ & 0.789 \\
\hline \multirow[t]{2}{*}{ Venous invasion } & Absent & 192 & 49.2 & 34.6 & 4.6 & & 1 & & \\
\hline & Present & 97 & 23.3 & 12.3 & 1.8 & $<0.001$ & 1.559 & $1.135-2.144$ & 0.006 \\
\hline \multirow[t]{2}{*}{ Histopathology } & Pap/well & 61 & 60.6 & 38.9 & 9.2 & & 1 & & \\
\hline & Other & 229 & 35.0 & 24.8 & 2.6 & 0.001 & 1.450 & $0.946-2.222$ & 0.088 \\
\hline \multirow[t]{2}{*}{ UICC pT } & $\mathrm{T} 0-2$ & 106 & 58.3 & 39.8 & 8.1 & & 1 & & \\
\hline & T3-4 & 184 & 29.9 & 21.7 & 2.3 & $<0.001$ & 1.436 & $0.989-2.084$ & 0.057 \\
\hline \multirow{2}{*}{ UICC pN } & No & 165 & 54.9 & 37.5 & 6.6 & & 1 & & \\
\hline & N1 & 125 & 20.9 & 14.9 & 2.0 & $<0.001$ & 1.797 & $1.300-2.483$ & $<0.001$ \\
\hline \multirow[t]{2}{*}{ UICC pStage } & Stage $0-2$ & 143 & 51.3 & 38.0 & 5.4 & & & & \\
\hline & Stage 3-4 & 147 & 29.9 & 17.5 & 2.3 & $<0.001$ & & & \\
\hline \multirow{2}{*}{ Residual tumor classification } & R0 & 228 & 46.2 & 32.0 & 3.7 & & 1 & & \\
\hline & $\mathrm{R} 1$ & 62 & 19.4 & 11.9 & 1.7 & $<0.001$ & 1.762 & $1.264-2.455$ & 0.001 \\
\hline
\end{tabular}

MET: Mesenchymal-epithelial transition factor; RON: recepteur d'origine nantais; Pap/well: Papillary/well-differentiated adenocarcinoma; other: moderately or poorly differentiated adenocarcinoma, and adenosquamous carcinoma; UICC: Union for International Cancer Control; R0: no residual tumor; R1: microscopic residual tumor.

and Takami et al. reported that the loss of MET signaling in hepatocytes enhanced chemical hepatocarcinogenesis in a mouse model (39). Thus, it is conceivable that the complete loss of MET and RON might attenuate these antitumor effects and result in cancer progression and poor prognosis, as shown in this study.

Although the complete loss of MET/RON was a significant poor prognostic factor in the univariate analysis, it was not significant in the multivariate analysis, indicating that the loss of MET/RON is not an independent factor. As described in our previous study, MET/RON overexpression has no correlation with conventional pathological findings and is an independent factor. This is also true in this study; however, complete loss of MET/RON was significantly associated with lymph-node metastasis and higher pathological stage. These results suggest that while overexpression of MET/RON is an independent poor prognostic factor, complete loss of $\mathrm{MET} / \mathrm{RON}$ can result in lymph-node metastasis, advancedstage disease and poor prognosis. Given that MET and RON are important in EMT, one can speculate that the loss of MET/RON results in EMT in cancer cells, promoting lymph-node metastasis.

Dual MET and RON inhibitors are expected as new therapeutic agents for cancer, and their effects have been demonstrated both in vitro and in vivo (40-43). A dual inhibitor might represent a breakthrough in the treatment not only of patients with advanced cholangiocarcinoma but also of high-risk postoperative patients. It has been reported that lymph-node metastasis is a poor prognostic factor in cholangiocarcinoma $(2,3)$, and adjuvant chemotherapy might be beneficial in these cases; however, patients with lymph- 
node metastasis frequently show complete loss of $\mathrm{MET} / \mathrm{RON}$, and dual inhibitors are potentially not effective in these patients. Even in patients with MET/RON overexpression, such an inhibitor might completely interrupt MET/RON signaling and thus have the opposite effect. Therefore, the indications for dual inhibitors should be precisely defined before administration, and overdose of such inhibitors should be avoided.

In conclusion, this study revealed that the cumulative survival rate was worse in patients with complete loss or overexpression of MET/RON than in those with intermediate MET/RON expression at all stages of EHCC. The expression status of MET/RON should be carefully evaluated not only to predict prognosis but also to define the indications for the use of MET/RON inhibitors.

\section{References}

1 Hezel AF and Zhu AX: Systemic therapy for biliary tract cancers. Oncologist 13: 415-423, 2008.

2 Nagino M, Ebata T, Yokoyama Y, Igami T, Sugawara G, Takahashi Y and Nimura Y: Evolution of surgical treatment for perihilar cholangiocarcinoma: a single-center 34-year review of 574 consecutive resections. Ann Surg 258: 129-140, 2013.

3 Kiriyama M, Ebata T, Aoba T, Kaneoka Y, Arai T, Shimizu Y and Nagino M: Prognostic impact of lymph node metastasis in distal cholangiocarcinoma. Br J Surg 102: 399-406, 2015.

4 Valle J, Wasan H, Palmer DH, Cunningham D, Anthoney A, Maraveyas A, Madhusudan S, Iveson T, Hughes S, Pereira SP, Roughton $\mathrm{M}$ and Bridgewater $\mathrm{J}$ : Cisplatin plus gemcitabine versus gemcitabine for biliary tract cancer. N Engl J Med 362: 1273-1281, 2010.

5 Okusaka T, Nakachi K, Fukutomi A, Mizuno N, Ohkawa S, Funakoshi A, Nagino M, Kondo S, Nagaoka S, Funai J, Koshiji M, Nambu Y, Furuse J, Miyazaki M and Nimura Y: Gemcitabine alone or in combination with cisplatin in patients with biliary tract cancer: a comparative multicentre study in Japan. Br J Cancer 103: 469-474, 2010.

6 Comoglio PM, Giordano S and Trusolino L: Drug development of MET inhibitors: targeting oncogene addiction and expedience. Nat Rev Drug Discov 7: 504-516, 2008.

7 Schmidt L, Junker K, Nakaigawa N, Kinjerski T, Weirich G, Miller M, Lubensky I, Neumann HP, Brauch H, Decker J, Vocke C, Brown JA, Jenkins R, Richard S, Bergerheim U, Gerrard B, Dean M, Linehan WM and Zbar B: Novel mutations of the MET proto-oncogene in papillary renal carcinomas. Oncogene 18: 2343-2350, 1999.

8 Park WS, Dong SM, Kim SY, Na EY, Shin MS, Pi JH, Kim BJ, Bae JH, Hong YK, Lee KS, Lee SH, Yoo NJ, Jang JJ, Pack S, Zhuang Z, Schmidt L, Zbar B and Lee JY: Somatic mutations in the kinase domain of the MET/hepatocyte growth factor receptor gene in childhood hepatocellular carcinomas. Cancer Res 59: 307-310, 1999.

9 Lee JH, Han SU, Cho H, Jennings B, Gerrard B, Dean M, Schmidt L, Zbar B and Vande Woude GF: A novel germ-line juxtamembrane MET mutation in human gastric cancer. Oncogene 19: 4947-4953, 2000.
10 Lee CT, Chow NH, Su PF, Lin SC, Lin PC and Lee JC: The prognostic significance of RON and MET receptor coexpression in patients with colorectal cancer. Dis Colon Rectum 51: 12681274,2008

11 Chen Q, Seol DW, Carr B and Zarnegar R: Co-expression and regulation of $M E T$ and $R O N$ proto-oncogenes in human hepatocellular carcinoma tissues and cell lines. Hepatology 26: 59-66, 1997.

12 Zhu GH, Huang C, Qiu ZJ, Liu J, Zhang ZH, Zhao N, Feng ZZ and Lv XH: Expression and prognostic significance of CD151, c-MET and integrin alpha3/alpha6 in pancreatic ductal adenocarcinoma. Dig Dis Sci 56: 1090-1098, 2011.

13 Kurokawa Y, Matsuura N, Kawabata R, Nishikawa K, Ebisui C, Yokoyama Y, Shaker MN, Hamakawa T, Takahashi T, Takiguchi S, Mori M and Doki Y: Prognostic impact of major receptor tyrosine kinase expression in gastric cancer. Ann Surg Oncol 21(Suppl 4): S584-590, 2014.

14 Nishida S, Hirohashi Y, Torigoe T, Nojima M, Inoue R, Kitamura H, Tanaka T, Asanuma H, Sato N and Masumori N: Expression of hepatocyte growth factor in prostate cancer may indicate a biochemical recurrence after radical prostatectomy. Anticancer Res 35: 413-418, 2015.

15 Maggiora P, Lorenzato A, Fracchioli S, Costa B, Castagnaro M, Arisio R, Katsaros D, Massobrio M, Comoglio PM and Flavia Di Renzo M: The RON and MET oncogenes are co-expressed in human ovarian carcinomas and cooperate in activating invasiveness. Exp Cell Res 288: 382-389, 2003.

16 Lee WY, Chen HH, Chow NH, Su WC, Lin PW and Guo HR: Prognostic significance of co-expression of RON and MET receptors in node-negative breast cancer patients. Clin Cancer Res 11: 2222-2228, 2005.

17 Maggiora P, Marchio S, Stella MC, Giai M, Belfiore A, De Bortoli M, Di Renzo MF, Costantino A, Sismondi P and Comoglio PM: Overexpression of the $R O N$ gene in human breast carcinoma. Oncogene 16: 2927-2933, 1998.

18 Zhou YQ, He C, Chen YQ, Wang D and Wang MH: Altered expression of the RON receptor tyrosine kinase in primary human colorectal adenocarcinomas: generation of different splicing $R O N$ variants and their oncogenic potential. Oncogene 22: 186-197, 2003.

19 Cheng HL, Liu HS, Lin YJ, Chen HH, Hsu PY, Chang TY, Ho CL, Tzai TS and Chow NH: Co-expression of RON and MET is a prognostic indicator for patients with transitionalcell carcinoma of the bladder. Br J Cancer 92: 1906-1914, 2005.

20 Thomas RM, Toney K, Fenoglio-Preiser C, Revelo-Penafiel MP, Hingorani SR, Tuveson DA, Waltz SE and Lowy AM: The RON receptor tyrosine kinase mediates oncogenic phenotypes in pancreatic cancer cells and is increasingly expressed during pancreatic cancer progression. Cancer Res 67: 6075-6082, 2007.

21 Ferrandina G, Martinelli E, Petrillo M, Prisco MG, Zucconi A, Santaguida S, Zannoni G, Scambia G and Ferlini C: Prognostic role of the recepteur d'origine nantais (RON) expression in ovarian cancer patients. Gynecol Oncol 111: 237-243, 2008.

22 Zhou D, Pan G, Zheng C, Zheng J, Yian L and Teng X: Expression of the RON receptor tyrosine kinase and its association with gastric carcinoma versus normal gastric tissues. BMC Cancer 8: 353, 2008. 
23 Follenzi A, Bakovic S, Gual P, Stella MC, Longati P and Comoglio PM: Cross-talk between the proto-oncogenes MET and RON. Oncogene 19: 3041-3049, 2000.

24 Watanabe H, Yokoyama Y, Kokuryo T, Ebata T, Igami T, Sugawara G, Mizuno T, Shimoyama $Y$ and Nagino $M$ : Prognostic value of hepatocyte growth factor receptor expression in patients with perihilar cholangiocarcinoma. Ann Surg Oncol 22: 2235-2242, 2015.

25 Koh YW, Hwang HS, Jung SJ, Park C, Yoon DH, Suh C and Huh J: Receptor tyrosine kinases MET and RON as prognostic factors in diffuse large B-cell lymphoma patients receiving RCHOP. Cancer Sci 104: 1245-1251, 2013.

26 Uddin S, Hussain AR, Ahmed M, Al-Dayel F, Bu R, Bavi P and Al-Kuraya KS: Inhibition of c-MET is a potential therapeutic strategy for treatment of diffuse large B-cell lymphoma. Lab Invest 90: 1346-1356, 2010.

27 Koh YW, Lee HJ, Ahn JH, Lee JW and Gong G: MET expression is associated with disease-specific survival in breast cancer patients in the neoadjuvant setting. Pathol Res Pract 210: 494-500, 2014.

28 Nakopoulou L, Gakiopoulou H, Keramopoulos A, Giannopoulou I, Athanassiadou P, Mavrommatis $\mathbf{J}$ and Davaris PS: c-MET tyrosine kinase receptor expression is associated with abnormal beta-catenin expression and favourable prognostic factors in invasive breast carcinoma. Histopathology 36: 313-325, 2000.

29 Sobin L, Gospodarowicz $M$ and Wittekind $C$ : TNM Classification of Malignant Tumours. Chichester: WileyBlackwell, 2010.

30 Miyamoto M, Ojima H, Iwasaki M, Shimizu H, Kokubu A, Hiraoka N, Kosuge T, Yoshikawa D, Kono T, Furukawa H and Shibata T: Prognostic significance of overexpression of c-MET oncoprotein in cholangiocarcinoma. Br J Cancer 105: 131-138, 2011.

31 Hida Y, Morita T, Fujita M, Miyasaka Y, Horita S, Fujioka Y, Nagashima K and Katoh H: Clinical significance of hepatocyte growth factor and c-MET expression in extrahepatic biliary tract cancers. Oncol Rep 6: 1051-1056, 1999.

32 Aishima SI, Taguchi KI, Sugimachi K, Shimada M, Sugimachi $\mathrm{K}$ and Tsuneyoshi M: c-ERBB-2 and c-MET expression relates to cholangiocarcinogenesis and progression of intrahepatic cholangiocarcinoma. Histopathology 40: 269-278, 2002.

33 Tajima $\mathrm{H}$, Matsumoto $\mathrm{K}$ and Nakamura T: Hepatocyte growth factor has potent antiproliferative activity in various tumor cell lines. FEBS Lett 291: 229-232, 1991.

34 Shiota G, Rhoads DB, Wang TC, Nakamura T and Schmidt EV: Hepatocyte growth factor inhibits growth of hepatocellular carcinoma cells. Proc Natl Acad Sci USA 89: 373-377, 1992.

35 Ronen D, Altstock RT, Firon M, Mittelman L, Sobe T, Resau JH, Vande Woude GF and Tsarfaty I: MET-HGF/SF mediates growth arrest and differentiation in T47D breast cancer cells. Cell Growth Differ 10: 131-140, 1999.
36 Shen K and Novak RF: FAS-signaling and effects on receptor tyrosine kinase signal transduction in human breast epithelial cells. Biochem Biophys Res Commun 230: 89-93, 1997.

37 Wang X, DeFrances MC, Dai Y, Pediaditakis P, Johnson C, Bell A, Michalopoulos GK and Zarnegar R: A mechanism of cell survival: sequestration of FAS by the HGF receptor Met. Mol Cell 9: 411-421, 2002.

38 Accordi B, Pillozzi S, Dell'Orto MC, Cazzaniga G, Arcangeli A, Kronnie GT and Basso G: Hepatocyte growth factor receptor cMET is associated with FAS and when activated enhances druginduced apoptosis in pediatric B acute lymphoblastic leukemia with TEL-AML1 translocation. J Biol Chem 282: 29384-29393, 2007.

39 Takami T, Kaposi-Novak P, Uchida K, Gomez-Quiroz LE, Conner EA, Factor VM and Thorgeirsson SS: Loss of hepatocyte growth factor/c-MET signaling pathway accelerates early stages of $N$-nitrosodiethylamine induced hepatocarcinogenesis. Cancer Res 67: 9844-9851, 2007.

40 Steinig AG, Li AH, Wang J, Chen X, Dong H, Ferraro C, Jin M, Kadalbajoo M, Kleinberg A, Stolz KM, Tavares-Greco PA, Wang T, Albertella MR, Peng Y, Crew L, Kahler J, Kan J, Schulz R, Cooke A, Bittner M, Turton RW, Franklin M, Gokhale P, Landfair D, Mantis C, Workman J, Wild R, Pachter J, Epstein $\mathrm{D}$ and Mulvihill MJ: Novel 6-aminofuro[3,2-c]pyridines as potent, orally efficacious inhibitors of cMET and RON kinases. Bioorg Med Chem Lett 23: 4381-4387, 2013.

41 Yan SB, Peek VL, Ajamie R, Buchanan SG, Graff JR, Heidler SA, Hui YH, Huss KL, Konicek BW, Manro JR, Shih C, Stewart JA, Stewart TR, Stout SL, Uhlik MT, Um SL, Wang Y, Wu W, Yan L, Yang WJ, Zhong B and Walgren RA: LY2801653 is an orally bioavailable multi-kinase inhibitor with potent activity against MET, MST1R and other oncoproteins and displays antitumor activities in mouse xenograft models. Invest New Drugs 31: 833-844, 2013

42 Kawada I, Hasina R, Arif Q, Mueller J, Smithberger E, Husain AN, Vokes EE and Salgia R: Dramatic antitumor effects of the dual MET/RON small-molecule inhibitor LY2801653 in nonsmall cell lung cancer. Cancer Res 74: 884-895, 2014.

43 Zeng JY, Sharma S, Zhou YQ, Yao HP, Hu X, Zhang R and Wang MH: Synergistic activities of MET/RON inhibitor BMS777607 and mTOR inhibitor AZD8055 to polyploid cells derived from pancreatic cancer and cancer stem cells. Mol Cancer Ther 13: 37-48, 2014. 